\title{
Comparison of Radiographic Results between Three Crossed Pinning and Four-Pin Radioulnar Transfixation Methods in the Treatment of Unstable Distal Radius Fracture
}

\author{
Danial Hosseinzadeh ${ }^{1}$, Naser Janmohammadi², Seyed Mokhtar Esmaeilnejad-Ganji ${ }^{3}$, Masoud Bahrami Frydoni ${ }^{4}$ \\ ${ }^{1}$ MD, Student Research Committee, School of Medicine, Babol University of Medical Sciences, Babol, Iran. \\ 2 Professor, Cancer Research Center, Health Research Institute, Babol University of Medical Sciences, Babol, Iran. \\ ${ }^{3}$ Associate Professor, Mobility Impairment Research Center, Health Research Institute, Babol University of Medical Sciences, Babol, Iran. \\ ${ }^{4}$ Assistant Professor, Clinical Research Development Center, Shahid Beheshti Hospital, Babol University of Medical Sciences, Babol, Iran.
}

\section{ABSTRACT}

\section{BACKGROUND}

Distal radius fractures are about one-sixth of the total referral fractures to the emergency department. With increase in distal radius fracture cases, especially in Iran, where many cases of trauma are reported, it seems necessary to determine a better treatment for distal radius fracture. This study was designed to compare radiographic results and side effects between three crossed pinning and four-pin radioulnar transfixation methods in the treatment of patients with unstable distal radius fracture.

\section{METHODS}

This randomized controlled trial study was conducted on the patients, with distal radius facture, aged 18-65 years, who were referred to the Emergency Department of Shahid Beheshti Hospital in Babol, Northern Iran. Patients with a history of bone surgery in the wrists were excluded from the study. Fifty patients were randomly assigned to the two groups of operation: three crossed pinning $(n=25)$ and four-pin radioulnar transfixation $(n=25)$. Radial length, palmar tilt, radial inclination and ulnar variance were evaluated immediately after surgery and at weeks 6, 12 and 24 of surgery.

\section{RESULTS}

No significant differences were found between the groups in age and gender. Radiographic results between the two groups showed no any significant differences in various follow-ups. Regarding the post-operative side-effects, pain was similar in 4 patients in each group. Also, pin tract infection was observed only in 1 patient in group of four-pin radioulnar transfixation. There were no significant differences between the two surgeries in the complications.

\section{CONCLUSIONS}

Based on the findings, similar outcomes were seen between three crossed pinning and four-pin radioulnar transfixation methods.

\section{KEY WORDS}

Radius, Fractures, Radiography
Corresponding Author: Dr. Masoud Bahrami Frydoni,

Department of Orthopedics, Babol University of Medical Sciences, Ganjafrooz Street, Babol,

Mazandaran, Iran.

E-mail: bahramimasoud478@gmail.com

DOI: $10.14260 /$ jemds/2019/566

Financial or Other Competing Interests: None.

How to Cite This Article:

Hosseinzadeh D, Janmohammadi N, Ganji $S M E$, et al. Comparison of radiographic results between three crossed pinning and four-pin radioulnar transfixation methods in the treatment of unstable distal radius fracture. J. Evolution Med. Dent. Sci. 2019;8(33):2597-2601, 10.14260/jemds/2019/566

Submission 16-06-2019, Peer Review 04-08-2019,

Acceptance 10-08-2019, Published 19-08-2019. 


\section{BACKGROUND}

Distal radius fractures are about one-sixth of the total referral fractures to the emergency department.(1) These fractures are seen in all age groups, resulting from falling on the ground with open hands in middle-aged people and elderly, but mainly due to the severe force resulting from falling or car accidents in young people. Based on the impact severity, the fracture site may show a collapse and severe shortness of bone without displacement.(1,2) There are various treatment methods, including surgical and non-surgical treatments for these types of fractures, but there is still a discrepancy regarding the choice of treatment method.(3-5)

The most complications associated with these fractures are intra-articular fractures. One of the main methods for the treatment of intra-articular fracture of distal radius is a closed reduction and percutaneous pinning (PCP). Although PCP with gypsum has been introduced as a cheaper and more stable method, there are reports on the displacement of the parts and collapses. These complications, such as radius shortening, dorsal angulation and joint failure, can be very problematic in patients. ${ }^{6,7)}$ Using this method, the number of pins and their place of entry varies according to the physician's opinion. Although there are several methods, there is still no agreement on better treatment options.

With increase in distal radius fracture cases, especially in Iran, where many cases of trauma are reported, it seems necessary to determine a better treatment for distal radius fracture. In the past, some treatment methods have been studied in a few studies in Iran, but so far, no study has been conducted to compare the treatment outcomes using two different PCP (radial and trans ulnar radial compared to crossed pinning radial side and ulnar side distal radius). Accordingly, this clinical trial study was designed to compare the complications and outcomes of treatment using these two methods of closed reduction and PCP in patients with unstable distal radius fracture.

\section{METHODS}

This randomized controlled trial study was conducted on the patients with distal radius facture aged 18-65 years old, who were referred to the Emergency Department of Shahid Beheshti Hospital in Babol, Northern Iran. Patients with a history of bone surgery in the wrists were excluded from the study. The intra-articular fractures included the distal radius fracture with expansion to the radiocarpal and radioulnar joint including Frykman's 7th and 8th classification.

Patients were randomly divided into the two groups of intervention (Crossed pinning and radioulnar transfixation) by a computer-generated randomization sequence with the opinion of a counselor. Regarding the fact that each one of pinning methods are effective in treating this type of fracture according to Rockwood and Green sources, patients were randomly assigned to either of these two methods.

Due to the fact that intra-articular fractures (type 7 and 8 of the Frykman) were included in the study, patients randomly divided into two groups had the same type of fracture according to Frykman's classification.

For patients undergoing closed reduction, the procedure was performed within 24 hours under general anesthesia and then by manual stretching and manipulation, while the cloth was rolled up to $20 \mathrm{~cm}$ below the wrist.

According to the following formula, the sample size was estimated as at least 22 patients in each group by the provided numbers as follows: $\mu \mathrm{A}=\mu \mathrm{B}=$ Mean $=12 ; \quad \kappa=\mathrm{nA} / \mathrm{nB}=1$; $\sigma=$ Standard deviation $=2 ; \quad \alpha=$ Type I error $=5 \% ; \quad \delta=$ noninferiority margin $=1.5 ; 1-\beta=$ Power $=80 \%$. By applying $15 \%$ for prediction of subjects dropping over the study, the final sample size will be 25 for each group.

$$
\begin{gathered}
n_{A}=\kappa n_{B} \text { and } n_{B}=\left(1+\frac{1}{\kappa}\right)\left(\sigma \frac{z_{1-\alpha}+z_{1-\beta}}{\mu_{A}-\mu_{B}-\delta}\right)^{2} \\
1-\beta=\Phi\left(z-z_{1-\alpha}\right)+\Phi\left(-z-z_{1-\alpha}\right) \quad, \quad z=\frac{\mu_{A}-\mu_{B}-\delta}{\sigma \sqrt{\frac{1}{n_{A}}+\frac{1}{n_{\theta}}}}
\end{gathered}
$$

After confirmation of fluoroscopy, two $1.6 \mathrm{~mm}$ pins were inserted from styloid of radius into the distal and lateral cortex in the styloid region and into the proximal cortex in the anterior region, and the two-pin angles ranged about 45 to 60 degrees based on the fracture surface, that ultimately yielded the desired stability. In the crossed pinning ulnar corner fixation group, the third pin entered the distal radius from the ulnar angle, whereas in the trans-ulnoradial pinning group, the third pin with a size of 1.5 was obliquely inserted in the distal to the fracture site and the fourth pin of with a size of 2 was transversely inserted in the proximal to the fracture site, from ulna to the radial bone and to the cortex in front of radius. The heads of the pins were left outside the skin and a long cast was taken for the patient's hand.

The movements of the fingers were started from the first day after fixation. In the fourth week of treatment, the long cast replaced by a short one. Pins were removed by the local anaesthetics after six weeks, and at the same time the patient's cast was also removed. Then the hand physiotherapy was performed on the wrist through the supination, pronation, flexion and extension, and also as movements of elbow and fingers, and were continued until the 12 th week. It was recommended the patient not to use the upper limb to move heavy objects for 12 weeks after starting treatment. The follow up of the patients included radiography at weeks 6,12 and 24 . In the radiographic examination, the anterior, posterior and lateral views of both wrists were collected at the start of study and after reduction and at weeks 6, 12 and 24, and compared with each other. The assessors of the outcomes were blinded to the groups.

Radiographic examination included the following 4 components

1. Radial length in the posteroanterior view that passed through the middle of the measurement of the distance between the two lines perpendicular to the longitudinal axis of the styloid radius, and the other through the ulnar distal articular surface.

2. Radial angle, which was an intermediate line angle that extends from the tip of styloid radius and the corner of medial facet and the line perpendicular to the longitudinal radius axis.

3. Volar rotation at the distal radius level in the lateral view.

4. Ulnar variance, which was the distance between the radial corners of the articular surface of the ulna and the corner of the radial articular surface. 
In terms of imaging, fracture reduction was considered well when dorsal angulation was less than 5 degrees and difference in radial shortening was less than $2 \mathrm{~mm}$. When dorsal angulation was 5-10 degrees and difference in radial shortening was 2 to 5 millimetres, it was acceptable. When dorsal angulation was more than 10 degrees and difference in radial shortening was more than $5 \mathrm{~mm}$, it was bad. The required information was entered into the checklist by oral interview with patients. Data were analysed by SPSS V.22 and statistical analysis was performed using Chi-square and Independent Samples t-test. P-value less than 0.05 was considered significant.

Informed consent was taken from all subjects. The study was confirmed by the Research Council and the Ethics Committee of Babol University of Medical Sciences (code: MUBABOL.HRI.REC.1394.125). It was also registered in the Iranian Registry of Clinical Trials website, with code IRCT2016112727797N1.

\section{RESULTS}

This study was performed on 50 patients with unstable distal radius fracture. Twenty-five patients $(50 \%)$ were randomly assigned to receive four-pin radioulnar transfixation and 25 patients $(50.0 \%)$ received three crossed pinning. The mean age of patients was $46.04 \pm 18.14$ years with a range age of 19 74 years. Other information is shown in Table 1 . Figure 1 indicates CONSORT flow diagram. As indicated in Table 2, no significant differences were seen in the radiographic parameters between three crossed pining and four-pin radioulnar transfixation groups at different follow-ups. Regarding postoperative complications, no any differences were observed between the two groups (Table 3).

\begin{tabular}{|c|c|c|c|}
\hline Variables & $\begin{array}{c}\text { Three Crossed } \\
\text { Pinning }(n=25) \\
\end{array}$ & $\begin{array}{l}\text { Four-pin Radioulnar } \\
\text { Transfixation }(n=25)\end{array}$ & p-Value \\
\hline Age (mean \pm SD) & $44.40 \pm 15.89$ & $47.68 \pm 12.35$ & 0.41 \\
\hline \multicolumn{3}{|c|}{ Sex (n [\%]) } & \multirow{3}{*}{0.25} \\
\hline Man & $9(36)$ & $14(56)$ & \\
\hline Woman & $16(64)$ & $11(44)$ & \\
\hline \multicolumn{3}{|c|}{ Occupation (n [\%]) } & \multirow{4}{*}{0.36} \\
\hline Housewife & $15(60)$ & $11(44)$ & \\
\hline Employee & $7(28)$ & $12(48)$ & \\
\hline Unemployed & $3(12)$ & $2(8)$ & \\
\hline \multicolumn{3}{|l|}{ Involved side (n [\%]) } & \multirow{3}{*}{0.06} \\
\hline Right & $16(64)$ & $17(68)$ & \\
\hline Left & $9(36)$ & $8(32)$ & \\
\hline \multicolumn{3}{|c|}{ Damage Mechanism (n [\%]) } & \multirow{4}{*}{0.1} \\
\hline Falling down & $19(76)$ & $14(56)$ & \\
\hline Fall from height & $1(4)$ & $7(28)$ & \\
\hline Accident & $5(20)$ & $4(16)$ & \\
\hline \multicolumn{4}{|c|}{ Table 1. Basic Information of Patients in The Two Study Groups } \\
\hline
\end{tabular}

\begin{tabular}{|c|c|c|c|}
\hline Variables & $\begin{array}{c}\text { Three Crossed } \\
\text { Pinning (n=25) }\end{array}$ & $\begin{array}{c}\text { Four-pin Radioulnar } \\
\text { Transfixation (n=25) }\end{array}$ & p-Value \\
\hline \multicolumn{5}{|c|}{ Radial Length } \\
\hline After surgery & $11.84 \pm 1.82$ & $12.32 \pm 1.79$ & 0.34 \\
\hline 6 weeks later & $13.30 \pm 4.34$ & $12.08 \pm 1.91$ & 0.36 \\
\hline 12 weeks later & $12.21 \pm 4.35$ & $11.56 \pm 1.93$ & 0.80 \\
\hline 24 weeks later & $12.09 \pm 4.23$ & $11.28 \pm 1.94$ & 0.11 \\
\hline \multicolumn{5}{|c|}{ Palmar Tilt } \\
\hline After surgery & $2.49 \pm 1.81$ & $1.84 \pm 2.23$ & 0.19 \\
\hline 6 weeks later & $2.49 \pm 2.10$ & $1.96 \pm 2.37$ & 0.34 \\
\hline 12 weeks later & $1.77 \pm 1.78$ & $2.12 \pm 2.50$ & 0.54 \\
\hline 24 weeks later & $2.23 \pm 2.39$ & $1.84 \pm 2.44$ & 0.52 \\
\hline \multicolumn{5}{|c|}{ Ulnar Variance } \\
\hline After surgery & $1.37 \pm 1.02$ & $1.12 \pm 0.92$ & 0.31 \\
\hline
\end{tabular}

\begin{tabular}{|c|c|c|c|}
\hline 6 weeks later & $1.16 \pm 1.02$ & $1.12 \pm 0.88$ & 0.86 \\
\hline 12 weeks later & $1.02 \pm 1.08$ & $1.08 \pm 0.86$ & 0.82 \\
\hline 24 weeks later & $1.35 \pm 1.04$ & $1.12 \pm 0.88$ & 0.36 \\
\hline \multicolumn{4}{|c|}{ Radial Inclination } \\
\hline After surgery & $19.93 \pm 4.13$ & $20.24 \pm 2.52$ & 0.68 \\
\hline 6 weeks later & $20.72 \pm 3.52$ & $19.44 \pm 2.67$ & 0.70 \\
\hline 12 weeks later & $18.12 \pm 3.73$ & $18.96 \pm 2.74$ & 0.34 \\
\hline 24 weeks later & $19.91 \pm 3.79$ & $18.80 \pm 2.73$ & 0.23 \\
\hline \multicolumn{4}{|c|}{ Table 2. Evaluation of Radiographic Variables in The Two Groups } \\
\hline
\end{tabular}

\begin{tabular}{|c|c|c|c|}
\hline Variables & $\begin{array}{l}\text { Three Crossed Pinning } \\
(n=25)\end{array}$ & $\begin{array}{c}\text { Four-Pin } \\
\text { Radioulnar } \\
\text { Transfixation } \\
(n=25)\end{array}$ & p-Value \\
\hline \multicolumn{3}{|l|}{ Pain (n [\%]) } & \multirow{3}{*}{0.45} \\
\hline Yes & $4(16)$ & $4(16)$ & \\
\hline No & $21(84)$ & $21(84)$ & \\
\hline \multicolumn{3}{|l|}{$\begin{array}{l}\text { Pin tract } \\
\text { infection }\end{array}$} & \multirow{3}{*}{0.40} \\
\hline Yes & $0(0)$ & $1(4)$ & \\
\hline No & $25(100)$ & $24(96)$ & \\
\hline
\end{tabular}

\section{DISCUSSION}

Given that the distal radius fracture is one of the most common fractures, it requires a suitable treatment to achieve the desired outcome, as inappropriate and inadequate treatment in reduction and its maintaining will disrupt daily living activity.(8)

In this study, radiological parameters such as radial length, palmar tilt, ulnar variance and radial inclination were measured in 4 periods for the patients in both groups. The results showed that there were no significant differences between the radiological factors in the two groups. It seems that there is no difference between two pinning methods in this type of distal radius unstable fractures. Also, no differences were seen in pain, complication and mobility limitation. Gradl et al.(9) In 2014, found that intramedullary nail and volar plate fixation pinning did not differ significantly in terms of radiologic and functional factors. Li-hai et al,(10) performed meta-analysis in 2015 and reported that both volar locking plate and external fixation methods are similar in terms of side effects and patient performance. Although Handol et al.(6) reported that two methods of PCP and Kapandji pinning could not be replaced by each other in the unstable distal radius fractures. Stein et al,(11) also studied casting and external fixation in distal radius fractures. They reported that the conditions for using these two methods are different, as a result, the radiological and functional findings of the patients will be different.(11) The reason for this difference could be the difference in the type of patient's choice and the type of surgical procedure. Therefore, the age of the patient and the quality of the bone, the type and shape of the fracture, the mechanism and severity of injury play a decisive role in the recovery of the patient.

Achieving the initial acceptable stretch and closed reduction in distal radius is not difficult, but it is difficult to maintain.(12) However, in treating the patient, the soft tissue condition, lifestyle, and associated illnesses should also be considered. The most important factors affecting the outcome of the treatment are the first radial length and then the volar rotation. (1) $^{2}$ 


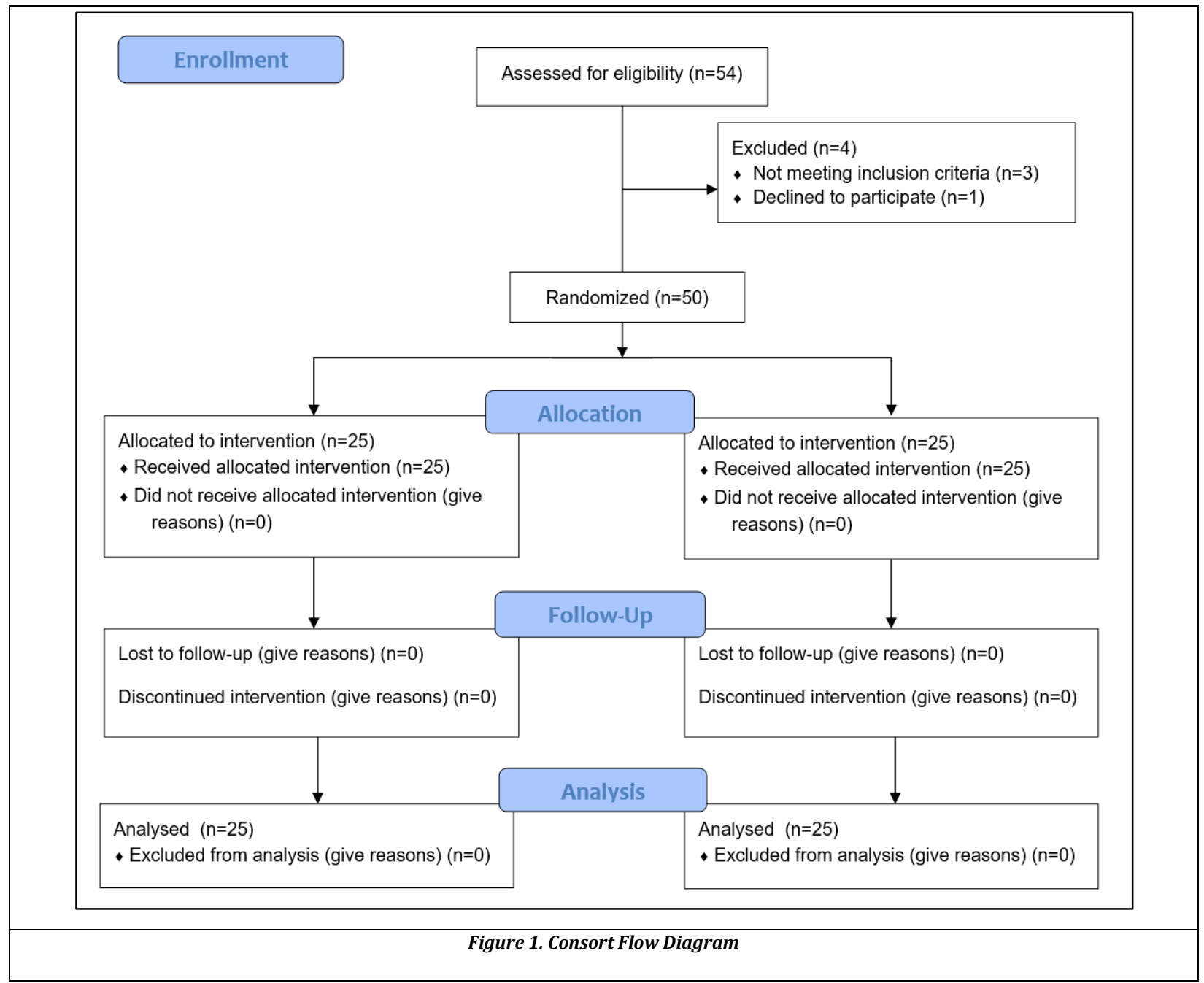

The average age of the patients studied in the group did not differ. In the study of Soleimanpour et al. (14) in 2010, it was also found that the two groups did not differ in age. Distal radius fracture is the most common upper limb fracture that occurs in all age groups, which is due to open hands falling in middle-aged and elderly people, and most of these patients have osteoporosis backgrounds. But in young people it occurs because of extreme force resulting from falling or driving accidents.(15) In this study, patients also suffered from fractures due to falling from altitude and fewer injuries due to an accident. Therefore, the average age of patients was lower than other studies.

In four-pin radioulnar transfixation group, the highest frequency was observed for men and in the group of three pins cross for women, although no significant relationship was observed. In their paper, Soleimanpour et al. stated that men are more frequent in both groups.(14) This discrepancy may be due to differences in the distribution of gender in the two populations.

The incidence of pain in the two groups is similar to the study by Soleimanpour et al.(14) In a study in 2004, Nash et al.(16) found that there was no difference between the two methods of pinning in terms of pain, swelling and stiffness. McQueen et al.(17) showed that a proper reduction would result in better outcomes in daily activities, strength of fist, range of wrist motion and the pain amount.
There was no significant relationship between the incidence of complications in the group. Given this conclusion, the two treatments are equally safe. Complications was only pin traction accompanied by infection, and there was no infection alone, and no bone healing or loosening of pins were seen. Depending on the severity of the impact, the fracture site might show collapse and severe bone defect without displacement and crushing. These factors influence the choice of treatment directly and they affect indirectly incidence of a postoperative complication. $(18,19)$

In terms of clinical criteria, the limitation of the motion of the wrist is considered to be a complication, but in our study, this complication was not observed. However, the same result was obtained in Soleimanpour's study, and the two pinning methods are completely similar in this regard.(14) The use of physical exercises significantly improves the patient's function in the amount of movement of the hand and wrist.

Performing a physiotherapy that takes place after removing the cast or fixator is helpful in obtaining the ideal movements amount in the joint, resulting in better healing and better prognosis.(20,21) Most studies have stated that the severity of anatomical damage during injury and the amount of residual deformity after treatment are effective in the results, especially the strength of the fist and the range of motion.(22) 
One of the limitations of the study is the lack of examination of effective variables such as physiotherapy and physical training. It is suggested that a study be conducted to assess the ability to return to daily living activity in two groups over a long period.

\section{CONCLUSIONS}

Based on the findings, the four-pin radioulnar transfixation and the three crossed pinning methods were not different in terms of radiological criteria and surgical complications.

\section{ACKNOWLEDGEMENT}

We would like to thank the Vice Chancellor for Research of Babol University of Medical Sciences for supporting our study. We are also tankful to Ms. Sekineh Kamali Ahangar, member of Clinical Research Development Center of Shahid Beheshti Hospital, for her help in preparing the manuscript.

\section{REFERENCES}

[1] Porrino JA, Maloney E, Scherer K, et al. Fractures of the distal radius: post-management radiographic characterization. AJR Am J Roentgenol 2014;203(4):84653.

[2] Tang JB. Distal radius fracture: diagnosis, treatment and controversies. Clin Plast Surg 2014;41(3):481-99.

[3] Henn CM, Wolfe SW. Distal radius fractures in athletes: approaches and treatment considerations. Sports Med Arthrosc 2014;22(1):29-38.

[4] Gao Y, Zhang W, Duan X, et al. Surgical interventions for treating radial head fractures in adults. Cochrane Database Syst Rev 2013;(5):CD008987.

[5] Kvernmo HD, Krukhaug Y. Treatment of distal radius fractures. Tidsskr Nor Laegeforen 2013;133(4):405-11.

[6] Handoll HH, Vaghela MV, Madhok R. Percutaneous pinning for treating distal radial fractures in adults. Cochrane Database Syst Rev 2007;(3):CD006080.

[7] Kim JY, Tae SK. Percutaneous distal radius-ulna pinning of distal radius fractures to prevent settling. J Hand Surg Am 2014;39(10):1921-5.

[8] Williksen JH, Husby T, Hellund JC, et al. External fixation and adjuvant pins versus volar locking plate fixation in unstable distal radius fractures: a randomized, controlled study with a 5-year follow-up. J Hand Surg Am 2015;40(7):1333-40.
[9] Gradl G, Mielsch N, Wendt M, et al. Intramedullary nail versus volar plate fixation of extra-articular distal radius fractures. Two year results of a prospective randomized trial. Injury 2014;45(Suppl 1):S3-S8.

[10] Li-Hai Z, Ya-Nan W, Zhi M, et al. Volar locking plate versus external fixation for the treatment of unstable distal radial fractures: a meta-analysis of randomized controlled trials. J Surg Res 2015;193(1):324-33.

[11] Stein H, Volpin G, Horesh Z, et al. Cast or external fixation for fracture of the distal radius: a prospective study of 126 cases. Acta Orthop Scand 1990;61(5):453-6.

[12] Weil YA, Mosheiff R, Firman S, et al. Outcome of delayed primary internal fixation of distal radius fractures: a comparative study. Injury 2014;45(6):960-4.

[13] Dario P, Matteo G, Carolina C, et al. Is it really necessary to restore radial anatomic parameters after distal radius fractures? Injury 2014;45(Suppl 6):S21-S6.

[14] Soleimanpour J, GHorbanzadeh M, Ganjpour J, et al. Comparison of outcomes and complications of 1-and 4week cast immobilization after distal radius surgery. J Kerman Univ Med Sci 2010;17(1):49-57.

[15] De França BEN, de Paula EJL, de Resende MR, et al. Distal radial fractures in patients over 60 years old: orthogonal plates versus volar plate. Rev Bras Ortop 2010;45(6):5905 .

[16] Nash CE, Mickan SM, Del Mar CB, et al. Resting injured limbs delays recovery: a systematic review. J Fam Pract 2004;53(9):706-12.

[17] McQueen M, Caspers J. Colles fracture: does the anatomical result affect the final function? J Bone Joint Surg Br 1988;70(4):649-51.

[18] Olivera GN, Ruchelli L, Iglesias S, et al. Minimally invasive plate osteosynthesis in distal radius fractures with metaphyseal extension: a series of 13 cases. Chirurgie de la Main 2015;34(5):227-33.

[19] Dée W, Klein W, Rieger H. Reduction techniques in distal radius fractures. Injury 2000;31(Suppl 1):48-55.

[20] Bozorg DA, Mehdinasab SAH, Alimi E. Repair of distal radius fractures by closed reduction and external fixation with or without pin placement. J Kermanshah Univ Med Sci 2013;17(12):1-10.

[21] Lenoble E, Dumontier C, Goutallier D, et al. Fracture of the distal radius. A prospective comparison between transstyloid and Kapandji fixations. J Bone Joint Surg Br 1995;77(4):562-7.

[22] Lewis S, Mostofi A, Stevanovic M, et al. Risk of tendon entrapment under a dorsal bridge plate in a distal radius fracture model. J Hand Surg Am 2015;40(3):500-4. 